RUNNING HEAD: Predicting university performance

Predicting university performance in Psychology: The role of previous performance and discipline specific knowledge

Lucy R. Betts ${ }^{1}$, Tracey J. Elder ${ }^{2}$, James Hartley ${ }^{2} \&$ Anthony Blurton ${ }^{2}$

\footnotetext{
${ }^{1}$ Nottingham Trent University, United Kingdom

${ }^{2}$ Keele University, United Kingdom

*Corresponding author. Division of Psychology, Nottingham Trent University, Nottingham, NG1 4BU

Email: lucy.betts@ntu.ac.uk Ph: +44 1158485558 Fax: +44 1158486829
} 


\begin{abstract}
Recent initiatives to enhance retention and widen participation ensure it is crucial to understand the factors that predict students' performance during their undergraduate degree. The present research used Structural Equation Modeling (SEM) to test three separate models that examined the extent to which British Psychology students' A-level entry qualifications predicted: (1) their performance in years $1-3$ of their Psychology degree, and (2) their overall degree performance. Students' Overall A-level entry qualifications positively predicted performance during their first year and overall degree performance, but negatively predicted their performance during their third year. Additionally, and more specifically, students' A-level entry qualifications in Psychology positively predicted performance in the first year only. Such findings have implications for admissions tutors, as well as for students who have not studied Psychology before but who are considering applying to do so at university.
\end{abstract}

Keywords: Student performance, Degree classifications, Entry qualifications, Psychology, Structural equation modeling 


\section{Predicting university performance in Psychology: The role of previous performance and}

\section{discipline specific knowledge}

The face of Higher Education in the UK is changing rapidly. Perhaps the most influential of these changes is the current Government's initiative to widen access to university by 2010. If this initiative succeeds, official figures suggest that half of our 18 - 30 year olds will attend university by this date (Clarke 2003). Such a dramatic shift in the demographics of the student population has consequences for both tutors and researchers in Higher Education. It has promoted investigation into: (i) those factors that influence students' experiences, and (ii) those that promote student retention at university (Smith \& Naylor 2001, 2005).

Examining the antecedents of success at university has primarily been carried out in two distinct areas: (1) the role of individual traits such as personality, and (2) the role of background variables such as previous performance as predictors of later performance. Although Robbins et al. (2004) argue that the role of psychological traits should not be overlooked when examining the antecedents of students' performance at university, the evidence from previous research is mixed. For example, some researchers argue that student engagement is one of the best predictors of learning and personal development (Carini, Kuh \& Klein 2006). Others conclude that intention to study, student identity, perceived behavioural control, anticipated regret, and motivation are important predictors of examination performance (Phillips, Abraham \& Bond 2003). Whilst yet others provide evidence that achievement goals and study strategies are important antecedents of performance (Fenollar, Roman \& Cuestras 2007). Together, these studies present a mixed picture of the relative importance of personality traits for university performance.

More recently, due to the relatively large proportion of unaccounted variance when personality traits are examined as determinants of university performance, some studies have examined the importance of students' entry qualifications as antecedents of performance. 
However, the findings of these studies are also mixed. Some Australian studies suggest that the relationship between entry qualifications and performance is a simple positive one (e.g., McKenzie \& Schweitzer 2001; Zeegers 2004), whereas other Australian and Dutch studies suggest that the relationship is more complex (e.g., Hofman \& Van den Berg 2000; McKenzie \& Gow 2004).

Research conducted by McKenzie and Schweitzer (2001) provided evidence of a simple positive relationship between previous academic performance and students' performance during their first year at university. Specifically, these investigators identified that previous academic performance accounted for $39 \%$ of the variance and was the strongest predictor of performance in the first semester of their first year. Nonetheless, McKenzie and Schweitzer (2001) stipulate that their results should be regarded with caution because less than half of the variance in performance was accounted for - implicating the role of other factors. Also, because McKenzie and Schweitzer (2001) did not examine the full trajectory of the students' performance, it remains unclear as to whether students' previous performance predicts performance throughout their degree.

To address the issue of sustained performance, Zeegers (2004) examined whether previous academic performance predicted current performance in first and third year Australian students studying Science. Using causal models, their results indicated that for both year groups, previous academic performance was the strongest predictor of current academic performance. However, for third year students, previous academic performance was assessed as performance during the previous academic year rather than entry qualifications. Consequently, it still remains unclear as to the extent to which students' entry qualifications are predictive of their overall degree classification.

These studies by McKenzie and Schweitzer (2001) and Zeegers (2004) suggest that students' who are successful prior to university continue to be successful at university. However, there is evidence to suggest that this relationship between previous performance 
and performance at university may be more complex. For example, in a study examining factors that enhance students' academic development during the first year at university, Keup (2006) reports that the performance of American students declined between high school and the first year of university. This finding suggests that performing well prior to university may not facilitate successful performance during the first year of university. Similar conclusions were drawn by Houston, Knox and Rimmer (2007); their results revealed that UK students' entry qualifications did not predict performance at university.

Hofman and Van den Berg (2000) provide further evidence concerning the complexity of the relationship between previous performance and university performance. Through the use of SEM, Hofman and Van den Berg (2000) determined that age, average grade in science, and the number of science subjects taken prior to university were predictive of Dutch females' but not Dutch males' performance at university in a range of subjects. Further, being female, being young, having studied more science subjects at secondary school, and having scored higher in these subjects predicted lower levels of performance. This finding seems counterintuitive because we would expect that performing well previously would be an important determinant of future success.

The findings of previous research thus suggest that the relationship between previous performance and students' performance at university may be complex. Furthermore, more specifically, what remains unclear is whether or not these patterns occur within the discipline of Psychology, since Psychology was rarely included in the disciplines in the research described. However, a recent study conducted by Diseth (2007) goes some way to address this issue. Diseth (2007) examined the relationship between course experiences, approaches to learning, effort, ability (defined as previous performance), and first-year examination grades in Norwegian Psychology students. Previous performance was both the strongest predictor, and also a direct predictor, of students' academic achievement. Further, the 
students' approaches to learning and course experiences were significant predictors of performance in the examination but effort was not.

Although the study by Diseth (2007) goes some way to demonstrate the relationship between previous performance and performance at university in Psychology students, two questions remain unanswered. First, because Diseth (2007) assessed performance using an examination administered in the first year, it remains unclear as to the predictive value of previous performance beyond the first year. Second, there are issues with the measurement of students' previous performance because students were asked to self-report their previous performance. It may be that some students under or over reported their performance (see Mayer et al. 2007). Consequently, to avoid these issues it is necessary (1) to examine the relationship between previous performance and performance at university across the students' degree and (2) to use the university's central administration records to overcome any reporting bias. We adopted both of these approaches in the present study.

Another likely antecedent of students' university performance is their experiences of the degree subject prior to university. Specifically, it is possible that having previously studied a subject would enhance performance at degree level because prior knowledge of a topic stimulates interest and learning in that topic (Tobias 1994). Indeed, Simonite (2004) reported that UK students studying maths at university with entry qualifications aligned more to their course content were more likely to succeed at university. However, we must note that Hofman and Van den Berg (2000) reported that, for young Dutch females, prior experience of their degree subject predicted lower performance at degree level. Consequently, although intuitively it makes sense that previous experience of a subject would lead to success at university, the importance of prior experience as a predictor of success remains ambiguous.

With regard to Psychology, the effect of prior experience of the subject for performance at degree level is largely unknown. However, Forbes and Thomson (2006) report that from their sample of 379 first year UK Psychology students, 95\% of those students with A-level 
qualifications in Psychology state that having a prior qualification in Psychology made their first year at university easier. Similarly, $67 \%$ of those students who had no previous experience of Psychology reported feeling disadvantaged. Therefore, it seems that students' experiences differ according to whether or not they have prior knowledge of Psychology before commencing a Psychology degree. Further, Toal (2007) argues that Psychology at Alevel must be a pre-requisite for acceptance on to a Psychology degree for two reasons: (1) to strengthen the academic status of Psychology and (2) to increase the standards of Psychology graduates. However, what still remains unclear is whether performing well in A-level Psychology prior to commencing a degree is beneficial for students' performance both initially and across their Psychology degree. Consequently, we explored this issue as part of the present study.

Our present study thus aimed to examine further the role of previous academic performance in Psychology on students' performance at university. In light of the previous research findings we wanted to further examine these complexities by exploring whether or not previous academic achievement, in the form of A-level entry qualifications, both generally and specifically in Psychology, would predict students' performance throughout all three years of their degree. And, in addition, we were interested in whether or not performance in the first-year would be related to that in both the second and the third year, and final degree performance, irrespective of A-level qualifications (see Figure 1). The advantages of SEM, as an analytical technique, are that it permits complex relationships to be examined and can do so without measurement error (Byrne 2001; Ullman 2006).

In short we tested whether or not:

(1) students' previous (overall A-level) performance was predictive of their performance in Psychology in the first, second and third year;

(2) students' previous (overall A-level) performance was predictive of their overall Psychology degree classification; 
(3) students' previous performance in A-level psychology was predictive of performance in Psychology during the first, second and third year of their undergraduate studies in psychology; and

(4) students' previous performance in A-level psychology was predictive of their overall Psychology degree classification.

We did not use students' performance in their first year of their degree to predict their overall degree classification because student performance during their first year was not taken in to consideration when calculating the overall degree performance.

\section{Insert Figure 1 here}

\section{Method}

Data were extracted from one cohort of undergraduate Psychology students. Specifically, data were available for students' performance on all the Psychology modules that they completed as part of their degree at Keele University during 2004-2007. It is important to note here that students studying Psychology at Keele do so as part of a joint honours degree. During the first two years of study, for each year, the Psychology components comprise two modules covering research methods and statistics and two modules covering theoretical aspects of Psychology. In the students' final year of study, they complete two theoretical modules, an elective module in a topic of their choice, and a research dissertation. Additionally, information is available concerning the students' entry qualifications and their overall degree classification. The final data set contained the complete results from 161 Psychology students (129 female and 32 male) with a mean age of $21.47(S D=.83)$ at the time of graduation. Data were excluded from a further 27 students because of missing information.

\section{Data coding}


Students' entry qualifications were coded according to the criteria applied by the University and College Admission Service (UCAS) for determining entry qualifications when applying to university (Anon, undated). Students' A-level grades are converted into points, with an A grade coded as 120 points, a B grade as 100 points, a $\mathrm{C}$ grade as 80 points, a D grade as 60 points, and an E grade as 40 points. Appropriate adjustments were made if students had completed other entry level qualifications. The point value of the students' entry qualifications were then combined to create a composite score of prior academic performance with higher scores indicating higher previous performance $(M=327.33, S D=81.94$, range 60-580). A similar criterion was applied to determine students' previous performance in Psychology with higher scores indicating higher previous performance in Psychology. If students had not got an entry qualification in Psychology a mark of zero was recorded $(M=$ 70.74, $S D=43.19$; excluding those students without Psychology $M=92.60, S D=20.16$ ).

Additionally, for this research, the final degree classification was calculated on the basis of the students' performance in the Psychology component of their degree. This was based on the University's guidelines (Jukes 2007), but by making appropriate adjustments to reflect the reduced number of modules on which this degree classification was based. Specifically, because the Psychology modules contribute to half of the students' overall degree classification, we halved the number of modules that were needed for the students to achieve each degree classification. The newly created degree classification was then recoded so that high scores indicated a higher award. For example, first class degree was coded as 5, a 2:1 as 4, a 2:2 as 3, a third as 2, and a pass as 1 . Based these calculations, 5 students obtained a first, 87 an upper second class, 64 a lower second class and 5 a third class degree.

\section{Results}

\section{Analysis overview}

Structural Equation Modeling (SEM), using Amos version 6, was used to test the hypothesised paths in Figure 1 in three separate models. In the present analysis, latent 
variables were created using the students' recorded marks for each module to represent the performance in each of the three years of their degree (see Streiner 2006). Paths were drawn between these latent variables because it was expected that performance in the previous year would predict performance in the subsequent year. Also, entered into the analysis was an indicator of the students' previous academic performance. Finally, the students' overall degree classification was entered, based upon their Psychology marks.

\section{Model One}

The first model was designed to examine the extent to which students' performance in all of their entry qualifications predicted their performance during their degree and overall. The final model (shown in Figure 2) was a good fit of the data. The Root Mean Square Error of Approximation $(\mathrm{RMSEA})=.032$ was acceptable because it was less than .05 (Browne \& Cudeck, 1993; Byrne, 2001). The Comparative Fit Index (CFI) = .99 and the Goodness of Fit Index $(\mathrm{GFI})=.93$ exceeded the recommended value of .90 (Bryant \& Yarnold, 1995; Byrne, 2001). Also, the chi-square value for the model was not significant, $\mathrm{X}^{2}(69)=80.28, p>.05$, indicating that the model was a good fit (Kline 2005; Miles \& Shevlin 2001).

Insert Figure 2 here

The results of the SEM suggest that the latent variables of academic performance for each year, using the students' performance on individual modules, are appropriate. Also, as expected, the students' performance in the first year positively predicts their performance in the second year: higher performance in the first year is predicted of higher performance in the second year. A similar path emerged between performance in the second year and performance in the third year. Again, higher performance in the second year was predictive of higher performance in the third year. 
The SEM revealed that the students' A-level entry qualifications were a significant predictor of students' performance during their first year at university and during their third year. For the first year, higher previous performance on A-levels was predictive of higher performance during the first year. However, the relationship between entry qualifications and performance in third year was negative: performing well previously was predictive of lower performance in the third year and lower previous performance predicted higher performance in the third year. This finding was surprising because intuitively it would make sense that higher entry qualifications would be predictive of higher overall performance. Additionally, overall entry qualifications predicted students' degree classification based on their performance in Psychology at a trend level. Specifically, higher previous performance was predictive of a higher overall degree classification.

As would be expected, the students' overall degree classification in Psychology was also predicted by their performance during their degree. Third year performance predicted overall degree performance with high scores being predictive of a higher overall degree classification. Also, at a trend level, performance during the second year predicted students' overall degree classification. Contrary to expectation, this was a negative relationship: achieving higher marks during the second year was predictive of a lower degree classification.

\section{Model Two}

The second model was designed to examine the extent to which performance in A-level Psychology predicted students' performance during their degree and their overall degree classification. The final model (shown in Figure 3) was a good fit of the data, exceeding all of the recommended fit criteria, $\mathrm{RMSEA}=.037, \mathrm{CFI}=.98, \mathrm{GFI}=.93$ and $\mathrm{X}^{2}(69)=84.37, p>$ .05 .

Insert Figure 3 here 
As with model one, the latent variables of academic performance for each year were appropriate. Also, as with model one, students' performance in one academic year positively predicted their performance in their next academic year: performance in the third year positively predicted the students' Psychology degree classification and at a trend level performance in the second year negatively predicted overall degree classification.

The analysis also implicated previous performance in A-level Psychology as a significant predictor of students' performance. Specifically, previous experience in Psychology positively predicted performance during the first year. Therefore, having a higher A-level entry qualification in Psychology was predictive of scoring higher in the first year. However, this advantage of having a higher entry qualification in Psychology was not evident for students' performance later in their degree. Specifically, the entry level qualification for Psychology failed to predict students' performance during the second year, during the third year, and students' overall Psychology degree classification. Therefore, it seems that previous performance in A-level Psychology was not important for students' overall performance at degree level in Psychology at Keele. Consequently, students who had not studied Psychology previously were not disadvantaged in terms of their overall Psychology degree performance.

\section{Model Three}

The third model was designed to combine model one and model two. Specifically, model three examined whether students' overall previous experience and students' previous experience in Psychology would predict their performance across the three years and their overall Psychology degree classification, when both predictors were entered into the same model. The final model (shown in Figure 4) was a good fit of the data meeting many of the recommended fit criteria, $\mathrm{RMSEA}=.035, \mathrm{CFI}=.98$ and $\mathrm{GFI}=.93, \mathrm{X}^{2}(78)=92.94, p>.05$. 
As with model one and model two, the latent variables of academic performance for each year were appropriate. Also, students' performance in one academic year positively predicted their performance in their next academic year; students' degree classification was positively predicted by their performance in the third year, and performance in the second year negatively predicted overall degree class at a trend level.

When overall entry qualifications and Psychology entry qualifications were entered at the same time into the analysis, both positively predicted performance in the first year. Therefore, higher overall previous performance and higher previous performance in Psychology were predictive of higher performance during the first year. Overall, entry qualifications also positively predicted performance in the third year: students with higher overall previous performance scored higher in the third year. Overall entry qualifications also positively predicted the Psychology degree classification at a trend level. Therefore, higher entry qualifications predicted a higher degree classification. However, Psychology entry qualifications failed to predict performance during the third year or overall degree classification. Also, neither overall entry qualifications nor Psychology entry qualifications predicted performance in the second year. Together, these findings suggest that previous performance in Psychology is not an important predictor for performance beyond the first year of a student's degree.

\section{Discussion}

The aim of the present study was to examine whether students' previous performance predicted their performance at university both initially and throughout their degree. Through the use of SEM, we were able to examine whether previous performance predicted the students' performance during each year of their degree and their overall degree classification based upon their Psychology marks. Further, we examined the relative predictive power of students' previous performance as: (1) all of their entry qualifications, (2) entry qualifications 
in Psychology, and (3) all of their entry qualifications and entry qualifications in Psychology when entered into the same model.

Overall A-level entry qualifications were predictive of students' performance during their Psychology degree. However, as previous research indicates (e.g., Hofman \& Van den Berg 2000; McKenzie \& Gow 2004), this relationship is complex and one that varies during the degree. During the first year, performing well previously positively predicted overall performance. As would be expected, students with higher entry qualifications had higher performance in the first year. Also, having higher A-level entry qualifications predicted a higher degree classification, but this relationship was only significant at a trend level and must be treated with caution. Further, the opposite of this relationship was evident when third year marks were considered: having higher entry qualifications was predictive of lower marks during the third year. Similarly, performing less well during the second year was predictive of higher performance in the third year.

At first glance, these findings seem counterintuitive because we would expect that students who had previously performed well would continue to do so during their degree. However, there are two potential explanations for these findings. First, those students with lower marks in the second year may have been motivated to improve their performance and this motivation may have been reflected in an improvement in their performance. There is some empirical evidence to suggest that, although UK students' motivation to master their subject decreases across their degree, their concerns about the grades they achieve increase (Liebermanh \& Remedios 2007). Second, it may be that by the time students have entered the third year, any previous advantage in terms of previous academic performance may have been reduced because of the nature of learning in Higher Education. Specifically, during the course of their degree students with lower entry qualifications may have developed the appropriate study skills and transferable skills needed to succeed at degree level (Haigh \& Kilmartin 1999). 
We were also able to identify, using SEM, the importance of previous experience in Psychology as a predictor of students' performance during their Psychology degree. We found that previous performance in A-level Psychology was only predictive of students' performance in their first year of their degree. Specifically, having higher entry qualifications in Psychology predicted higher performance during the first year. This finding provides additional empirical support for the students' accounts of feeling disadvantaged during their first year at university studying Psychology when they have no previous experience of the discipline (Forbes \& Thomson, 2006). However, we found no other significant relationship between students' previous entry qualifications in Psychology and their later performance in Psychology. Further, we found no evidence of a relationship between entry qualifications in Psychology and overall Psychology degree classification. These findings suggest that any possible advantage of having studied Psychology prior to commencing a Psychology degree at university is relatively short-lived.

In the final model that we tested, we simultaneously examined the influence of students' overall previous performance and their previous performance in Psychology as predictors of performance during their Psychology degree and their overall degree performance in Psychology. As with the first two models, a complex pattern of results emerged. During the first year, higher performance was predicted by higher performance in students' overall entry qualifications and in students' Psychology entry qualification. Overall entry qualifications also predicted performance during the third year and students' overall degree classification. Specifically, higher entry qualifications were predictive of higher performance during the third year and a higher overall degree classification at a trend level. Conversely, students' performance in their Psychology entry qualifications failed to significantly predict performance beyond the first year.

Together, the findings of the three models indicate that overall entry qualification performance is important for Psychology students' performance during their degree and for 
their overall Psychology degree classification. However, more interestingly, the experience of Psychology before university failed to predict students' performance during their Psychology degree beyond the first year of the course. Similarly, students' overall Psychology degree classification was not predicted by their previous experience of Psychology. This finding, especially if it can be replicated in other studies, has a number of implications for admissions tutors, university personnel and students.

For admissions tutors and university personnel, our research suggests that previous experience of Psychology is a poor indicator of students' overall performance during their degree. This finding suggests, therefore, that it is necessary for admission tutors to consider other factors when determining whether or not to offer students a place on a Psychology course. Further, our findings also suggest that there are issues with the predictive ability of overall entry points as a method of predicting success at university. Specifically, we found that overall entry qualifications were a negative predictor of students' performance in the third year and that overall entry qualifications were only a weak predictor of their overall degree classification. Consequently, admissions tutors may need to look beyond these factors when trying to determine the likely success of a student at university. Further, other factors such as personality traits may also be useful for admissions tutors to consider when determining students' likely success.

With regard to students, our findings are particularly encouraging for those students who have no previous experience of studying Psychology but who are considering studying Psychology at university. Previous research has indicated that students who have no prior experience of studying Psychology before commencing a degree in Psychology report feeling disadvantaged, and those students who have studied Psychology previously report finding the subject easier because of their prior knowledge (Forbes \& Thomson 2006). However, through the use of SEM, we were able to demonstrate that any advantage that those students who have studied Psychology previously may have experienced did not extend beyond the 
first year of their degree. As such, students should not be discouraged from studying Psychology if they have no previous experience of the subject. These findings are also encouraging given the number of different Psychology A-level specifications that there are, and the concerns that some tutors have that some of these specifications do not provide students with appropriate skills for Higher Education (Green 2007; Toal 2007). Also, our results indicate that concern over the different specifications may be of little importance because entry qualifications in Psychology did not predict performance beyond the first year. The present findings, in particular, provide no empirical support for Toal's (2007) claim that requiring students to complete A-level Psychology before they complete a degree will raise academic standards.

On the other hand, our results also indicate that students' without previous experience of Psychology, or those who have performed less well in their Psychology entry qualification, do perform less well during the first year. One potential explanation here is that students without experience of Psychology, or those with low marks, may lack some of the necessary skills to succeed during the first year (Green 2007). If this is the case, then these students would benefit from additional support to aid their transition to university. For example, new technology could be used to support the students' transition, to provide social support networks, and to focus specifically on academic skills and concerns (see e.g., Harley, Winn, Pemberton \& Wilcox 2007; Pratt et al. 2000). Such support may serve as a way of reducing any potential dropout from this group of students because they are finding the course difficult. Future research in this area is vital, given the drive to increase participation in Higher Education and to reduce student dropout.

Although the present research is one of the first studies to examine the influence of students' entry qualifications across their degree and for their overall degree classification, it is not without its limitations. As with previous research in this area, less than fifty percent of the variance in performance was accounted for by the students' previous performance. 
Therefore, as suggested by McKenzie and Schweitzer (2001), other factors are also important in predicting students' performance. Nonetheless, as with previous research, we have found that previous performance is an important predictor of students' success during their degree. Further, we have achieved this whilst overcoming the limitations of previous studies by avoiding the use of self-reports of performance, and also by examining the relationships across the whole degree programme. In future, researchers could extend this approach that we have adopted and examine the role of personality variables in the relationship between entry qualifications and performance in each year and final degree performance.

In summary, through the use of SEM, we have examined the relationships between students' entry qualifications, their performance during their Psychology degree and their overall degree classification in Psychology. The findings demonstrate that these relationships are complex but that previous performance in A-level Psychology is not advantageous for students' overall degree classification - although there is some advantage during the first year of study. Together, these findings have implications for students deciding whether or not to pursue Psychology at degree level and for those who have not studied the subject previously. It would be wise, however, to replicate studies of this type in other joint and single-honours institutions in order to assess the generality of our findings. 
References

Anon. (undated), The UCAS tariff. Retrieved from http://www.ucas.com/candq/tariff/tariff_sep06.doc viewed 27 $7^{\text {th }}$ August 2007.

Browne, M. W. and Cudeck, R. 1993. Alternative ways of assessing model fit. In Testing structural equation models, ed K. A. Bollen and J. S. Long, 136-162. Newbury Park: Sage Publications.

Bryant, F. B., and Yarnold, P. R. 1995. Principal-components analysis and exploratory and confirmatory factor analysis. In Reading and understanding multivariate statistics, ed. L. G. Grimm and P. R. Yarnold, 99-136. Washington: American Psychological Society. Byrne, B. M. 2001. Structural equation modeling with AMOS: basic concepts, applications and programming. Mahwah: Lawrence Erlbaum Associates, Publishers.

Carini, R. M., G. D. Kuh, and S. P. Klein 2006. Student engagement and student learning: testing the linkages. Research in Higher Education 47: 1-32.

Clarke, C. 2003, January. The future of higher education: White paper presented to parliament retrieved from by the secretary of state for education and skills by command of her majesty. Retrieved from:

http://www.dcsf.gov.uk/hegateway/strategy/hestrategy/word/hewhitepaper.doc on $23^{\text {rd }}$ August 2007.

Diseth, A. 2007. Approaches to learning, course experience and examination grade among undergraduate psychology students: testing of mediator effects and construct validity. Studies in Higher Education 32: 373-388.

Fenollar, P., S. Roman, and P. J. Cuestas. 2007. University students' academic performance: An integrative conceptual framework and empirical analysis. British Journal of Educational Psychology 77: 873-891.

Forbes, D., and K. Thompson. 2006, June. First level students' expectations versus subsequent perceptions of the reality and the extent to which these predict performance. 
Paper presented at the Psychology Learning and Teaching Conference, York St. John University College, York, UK.

Green, S. 2007. The cookbook approach: A recipe for disaster? The Psychologist 20: 610-611.

Haigh, M. J., and M. P. Kilmartin. 1999. Student perceptions of the development of personal transferable skills. Journal of Geography in Higher Education 23: 195-206.

Harley, D., S. Winn, S. Pemberton, and P. Wilcox. 2007. Using texting to support students' transition to university. Innovations in Education \& Teaching International 44: 229241.

Hofman, A., and M. Van den Berg. 2000. Determinants of study progress: The impact of student, curricular, and contextual factors on study progress in university education. Higher Education in Europe 25: 93-110.

Houston, M., H. Knox, and R. Rimmer. 2007. Wider access and progression among full-time students. Higher Education 53: 107-146.

Jukes, S. 2007. Academic regulations \& guidance for staff and students: Annexes section A degree classification schemes. Retrieved from http://www.keele.ac.uk/depts/aa/regulationshandbook/degreeclass.htm on $10^{\text {th }}$ October 2007.

Keup, J. R. 2006. Promoting new-student success: Assessing academic development and achievement among first-year students. New Directions for Student Services 114: 27-46.

Kline, R. B. 2005. Principles and practice of structural equation modelling $\left(2^{\text {nd }}\right.$ ed). New York: Guilford Press.

Liebermanh, D. A., and R. Remedios. 2007. Do undergraduates' motives for studying change as they progress through their degrees? British Journal of Educational Psychology 77: 379-395. 
Mayer, R. E., A. T. Stull, J. Campbell, K. Almeroth, B. Bimber, D. Chun, et al. 2007. Overestimation bias in self-reported SAT scores. Education Psychology Review 19: 443454.

McKenzie, K., and K. Gow. 2004. Exploring the first year academic achievement of school leavers and mature-age students through structural equation modelling. Learning and Individual Differences 14: 107-123.

McKenzie, K., and R. Schweitzer. 2001. Who succeeds at university? Factors predicting academic performance in first year Australian university students. Higher Education Research \& Development 20: 21-33.

Miles, J., and M. Shevlin. 2001. Applying regression and correlation: A guide for students and researchers. London: Sage Publications.

Pratt, M., W., B. Hunsberger, S. Pancer, S. Alisat, C. Bowers, K. Mackey et al. (2000). Facilitating the transition to university: Evaluation of a social support discussion intervention program. Journal of College Student Development 41: 427-441.

Phillips, P., C. Abraham, and R. Bond. 2003. Personality, cognition, and university students' examination performance. European Journal of Personality 17: 435-448.

Robbins, S. B., K. Lauver, H. Le, D. Davis, R. Langley and A. Carlstorm. 2004. Do psychosocial and study skill factors predict college outcomes? A meta-analysis. Psychological Bulletin 130: 261-288.

Simonite, V. 2004. Multilevel analysis of relationship between entry qualifications and trends in degree classifications in mathematical sciences: 1994-2000. International Journal of Mathematical Education in Science and Technology 35: 355-344.

Smith, J. P., and R. A. Naylor. 2001. Dropping out of university: A statistical analysis of the probability of withdrawal for UK university students. Journal of the Royal Statistical Society Series A 164: 389-405. 
Smith, J., and R. Naylor. 2005. Schooling effects on subsequent university performance:

Evidence for the UK university population. Economics of Education Review 24: 549562.

Streiner, D. L. 2006. Building a better model: An introduction to structural equation modelling. Canadian Journal of Psychiatry 51: 317-324.

Toal, J. 2007. Teaching A-level psychology: Myth and reality. The Psychologist 20: 612-613.

Tobias, S. 1994. Interest, prior knowledge, and learning. Review of Educational Research 64: 37-54.

Ullman, J. B. 2006. Structural equation modeling: Reviewing the basics and moving forward. Journal of Personality Assessment 87: 35-50.

Zeegers, P. 2004. Student learning in higher education: a path analysis of academic achievement in science. Higher Education Research \& Development 23: 35-56. 
Figure Captions

Figure 1. The hypothesised relationships between students' previous performance, performance during each year of the degree and overall degree classification.

Figure 2. Model one: the final SEM for the relationship between students' overall A-level performance, performance during each year of the degree and overall degree classification $\dagger p$ $\leq .086, * p<.05, * * p \leq .01$ and $* * * p \leq .001$.

Figure 3. Model two: the final SEM for the relationship between students' Psychology Alevel performance, performance during each year of the degree and overall degree classification $\uparrow p=.095, * p<.05, * * p \leq .01$ and $* * * p \leq .001$.

Figure 4. Model three: the final SEM for the relationship between students' overall A-level performance, Psychology A-level performance, performance during each year of the degree and overall degree classification $\uparrow p=.072, * p<.05, * * p \leq .01$ and $* * * p \leq .001$ 


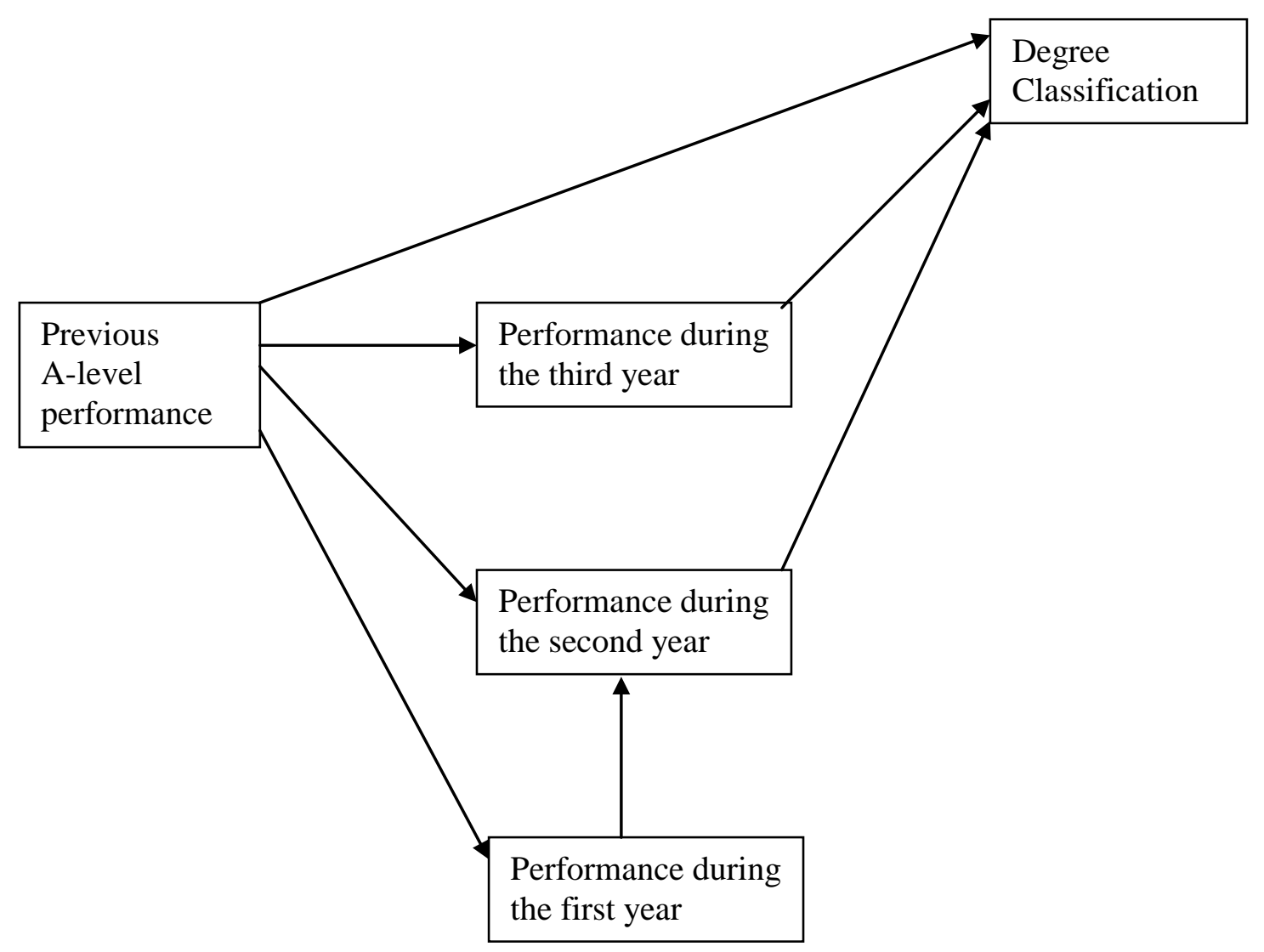




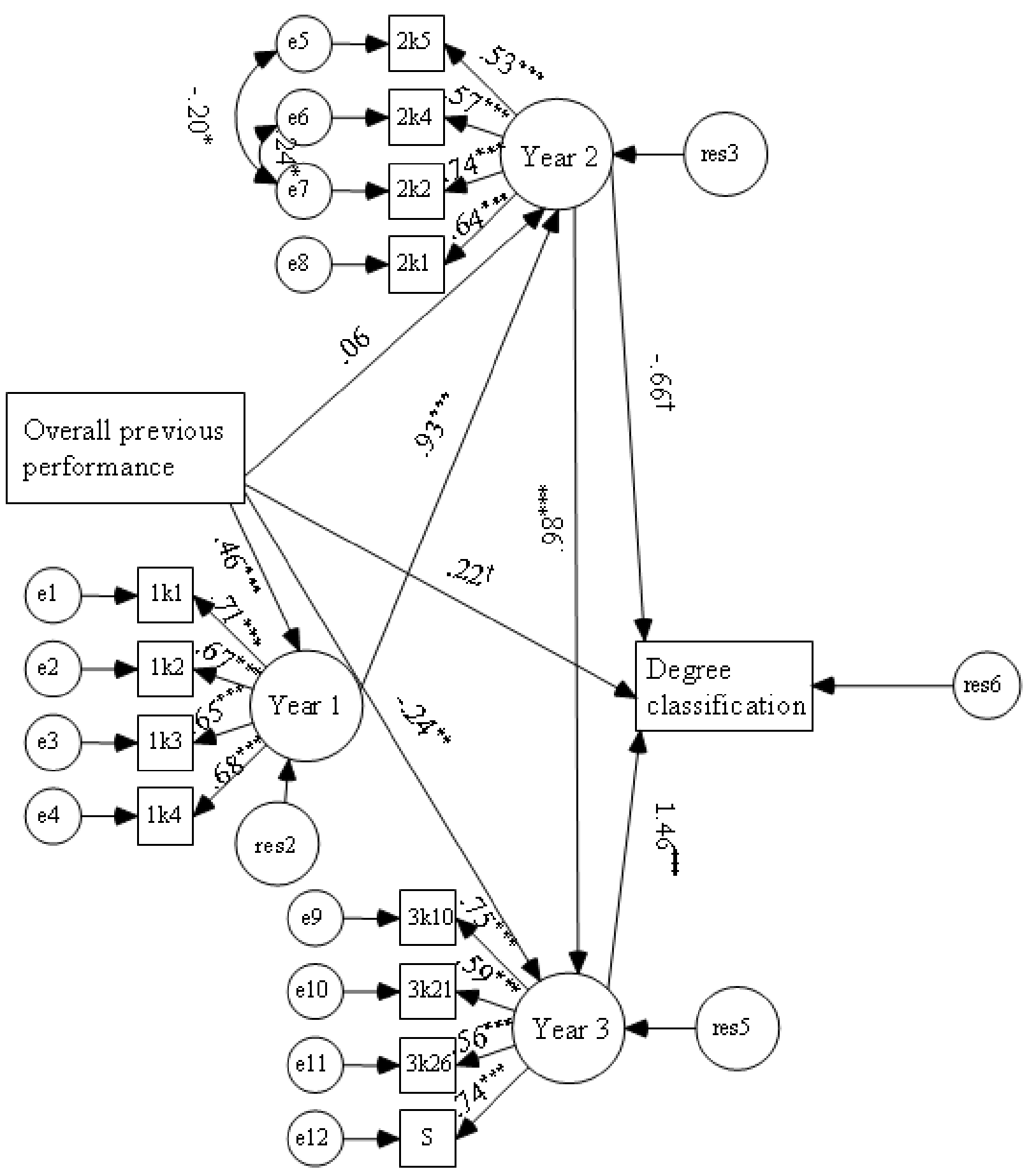




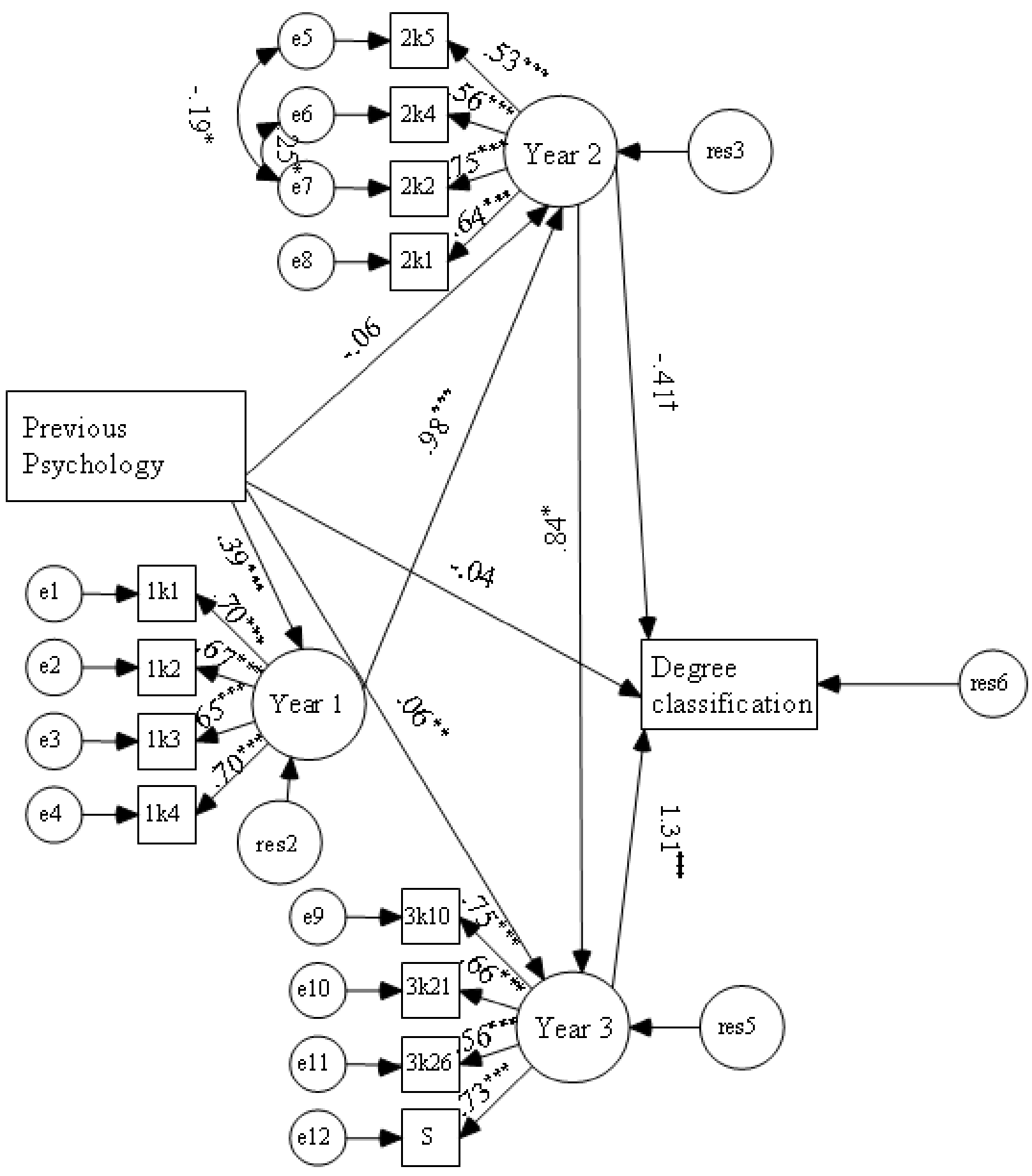




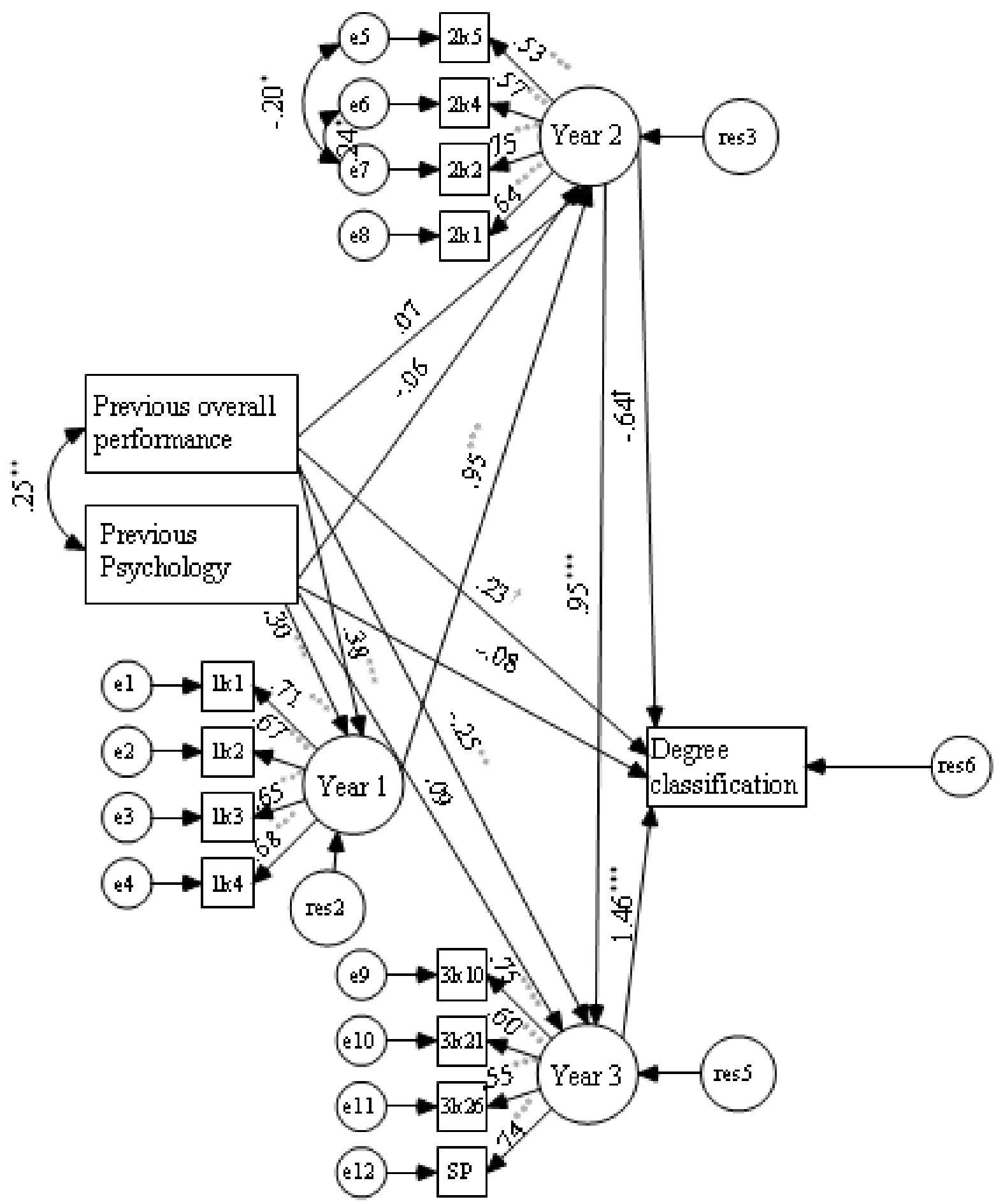

